\title{
Towards real-time detection of tumor margins using photothermal imaging of immune-targeted gold nanoparticles
}

This article was published in the following Dove Press journal:

International Journal of Nanomedicine

27 August 2012

Number of times this article has been viewed

\section{Kobi Jakobsohn \\ Menachem Motiei \\ Moshe Sinvani \\ Rachela Popovtzer}

Faculty of Engineering and Institute of Nanotechnology and Advanced Materials, Bar Ilan University, Ramat Gan, Israel
Correspondence: Rachela Popovtzer School of Engineering, Bar-llan University, Ramat Gan 52900, Israel

$\mathrm{Tel}+972353 \mid 7509$

$\mathrm{Fax}+97235317509$

Email rachela.popovtzer@biu.ac.il
Background: One of the critical problems in cancer management is local recurrence of disease. Between $20 \%$ and $30 \%$ of patients who undergo tumor resection surgery require reoperation due to incomplete excision. Currently, there are no validated methods for intraoperative tumor margin detection. In the present work, we demonstrate the potential use of gold nanoparticles (GNPs) as a novel contrast agent for photothermal molecular imaging of cancer.

Methods: Phantoms containing different concentrations of GNPs were irradiated with continuous-wave laser and measured with a thermal imaging camera which detected the temperature field of the irradiated phantoms.

Results: The results clearly demonstrate the ability to distinguish between cancerous cells specifically targeted with GNPs and normal cells. This technique, which allows highly sensitive discrimination between adjacent low GNP concentrations, will allow tumor margin detection while the temperature increases by only a few degrees Celsius (for GNPs in relevant biological concentrations).

Conclusion: We expect this real-time intraoperative imaging technique to assist surgeons in determining clear tumor margins and to maximize the extent of tumor resection while sparing normal background tissue.

Keywords: photothermal imaging, gold nanoparticles, molecular imaging

\section{Introduction}

Cancer is a leading cause of death worldwide. ${ }^{1}$ One of the critical problems in cancer management is local recurrence of disease. Between $20 \%$ and $30 \%$ of patients who undergo tumor resection surgery require reoperation because of incomplete excision. ${ }^{2,3}$ Currently, tumor margins are examined using conventional histological tests which are usually performed following the surgical procedure. A few methods have been developed in recent years for real-time intraoperative tumor margin detection with some success, including diffusive reflectance, ${ }^{4,5}$ radiofrequency-based detection, ${ }^{6}$ and targeted fluorescence imaging. ${ }^{7}$ However, there remains an urgent need to develop a highly specific and sensitive intraoperative real-time tumor margin detection method which will reduce the risk of cancer recurrence and the need for reoperation.

During the last decade, much research has focused on developing nanoparticles which enhance scattering or absorption in the near infrared region because of the relatively high transmittance of tissue in that region. Particles such as fluorescence dyes, gold nanoshells, and gold nanorods have been utilized either as diagnostic tools ${ }^{8-10}$ or as photothermal therapy-mediated agents..$^{8,9,11-14}$ 
Gold nanorods have gained much attention as a diagnostic tool due to their biocompatibility, their relatively easy fabrication and bioconjugation with biomolecules for targeting, their unique optical properties, and enhanced optical extinction coefficient as compared with conventional fluorescence dyes $;{ }^{15,16}$ by changing their size and aspect ratio, their surface plasmon resonance wavelength and absorption to scattering coefficient ratio can be tuned and controlled. ${ }^{15}$ Therefore, they have been widely utilized as near infrared, ${ }^{14}$ photoacoustic, ${ }^{17}$ Raman scattering, ${ }^{8}$ and diffusion reflection ${ }^{18,19}$ imaging contrast agents.

In addition to research regarding early detection of cancer, gold nanorods have been utilized as photothermal therapymediated agents. In these studies, the absorption properties of gold nanorods in the surface plasmon resonance wavelength are used to elevate temperature to $50^{\circ} \mathrm{C}$ and above, usually using lasers with a high optical output (above $10 \mathrm{~W} / \mathrm{cm}^{2}$ for about 20 minutes) in order to achieve effective denaturation and coagulation of cellular proteins, as well as cell death. ${ }^{11,12,20,21}$

An in vitro proof of concept for photothermal imaging using targeted gold nanoparticles (GNPs) is demonstrated in this paper. By selectively increasing the temperature of GNPs that specifically target and decorate the surface of cancer cells, we can distinguish between cancerous and noncancerous cells (ie, normal background tissue). We show that this technique has the ability to discriminate sensitively between adjacent concentrations of GNPs, while the temperature of the sample is elevated by only a few degrees Celsius. This is important because elevation of temperature to above $40^{\circ} \mathrm{C}$ may denature proteins and release heat shock proteins. ${ }^{11}$

Using a thermal camera, the photothermal imaging technique overcomes the inevitable background signal caused by light scattering from tissue. Another important advantage of this imaging technique is the use of the absorption properties of GNPs rather than their scattering properties. Imaging techniques based on the scattering properties of GNPs suffer from relatively high background noise and low contrast due to the relatively high scattering of tissue. By utilizing only the absorption properties of GNPs, higher contrast between the targeted cancer cells and normal background tissue can be achieved.

\section{Materials and methods}

\section{Nanoparticle synthesis} and characterization

Gold nanospheres with a diameter of $30 \mathrm{~nm}$ were synthesized using sodium citrate according to the methodology described by Enüstün and Turkevich. ${ }^{22}$ Gold nanorods (25 nm × $65 \mathrm{~nm}$ ) were synthesized using the seed-mediated growth method. ${ }^{23}$ Particle size, shape, and uniformity were measured using transmission electron microscopy. For the bioconjugation process, a protective layer of poly(ethylene glycol) (PEG) was adsorbed onto the surfaces of the gold nanospheres in order to prevent aggregation. The PEG layer consisted of a mixture of heterofunctional PEGs (SH-PEG-OCH ${ }_{3}$, about $85 \%$, molecular weight approximately $5 \mathrm{kDa}$ and an $\mathrm{SH}-$ PEG-COOH, about 15\%, molecular weight approximately $3.4 \mathrm{kDa}$, Creative PEGWorks, Winston-Salem, NC). For cancer cell targeting, heterofunctional PEGs were covalently conjugated with an anti-epithelial growth factor receptor (EGFR) monoclonal antibody (Erbitux ${ }^{\circledR}$, Merck KGaA, Darmstadt, Germany), using 1-ethyl-3-(3'-(dimethylamino) propyl)carbodiimide and sulfo-NHS (Thermo Fisher Scientific, Waltham, MA). ${ }^{24,25}$ Bioconjugation of the gold nanorods to the anti-EGFR antibody was achieved according to the method described by Lvov et al, ${ }^{26}$ using polystyrene sulfonate.

\section{Phantoms}

Solid phantoms were prepared in order to simulate the optical properties of skin tissue. ${ }^{27}$ Phantoms were prepared using $3 \times 10^{-3}$ percent of India ink as an absorbing component and 2\% of Intralipid (Lipofundin MCT/LCT 20\%, B Braun Melsungen AG, Melsungen, Germany) as a scattering component. ${ }^{28}$ Gold nanospheres $(30 \mathrm{mg} / \mathrm{mL})$ or gold nanorods $(5 \mathrm{mg} / \mathrm{mL})$ were added to the phantom solutions, achieving final gold concentrations of $0.002,0.02,0.022$, $0.03,0.04$, and $0.1 \mathrm{mg} / \mathrm{mL}$.

In order to prepare solid phantoms, the solutions were heated and mixed at a temperature of approximately $90^{\circ} \mathrm{C}$ while 1\% agarose powder (SeaKem LE Agarose, Lonza, Allendale, NJ) was slowly added. The heated phantom solutions were cooled under vacuum conditions to avoid formation of bubbles. All phantoms were poured into a 24-well plate (16 mm diameter wells), each well containing different concentrations of gold.

\section{Cell preparation and bioconjugation}

A431 human head and neck cancer cells $\left(2.5 \times 10^{6}\right)$, which are known to express an extremely high level of EGFR, ${ }^{29}$ were cultured in $5 \mathrm{~mL}$ of Dulbecco's modified Eagle's medium containing $5 \%$ fetal calf serum, $0.5 \%$ penicillin, and $0.5 \%$ glutamine at $37^{\circ} \mathrm{C}$ under $5 \% \mathrm{CO}_{2}$. For cell-GNP conjugation, $1 \mathrm{~mL}$ of cell suspension $\left(2.5 \times 10^{6} / \mathrm{mL}\right)$ was mixed with $1 \mathrm{~mL}$ of antibody-coated gold nanorod solution $(5 \mathrm{mg} / \mathrm{mL})$, and allowed to interact for 30 minutes at room temperature. 
Then, the solution was centrifuged three times at $1000 \mathrm{rpm}$ for 5 minutes to wash out unbound gold nanorods, and after each centrifugation, the mixture was redispersed in phosphate-buffered solution ( $1 \mathrm{~mL}$ total volume).

\section{Experimental setup}

This experiment was designed to image the distribution of temperature over the sample area under laser illumination. The laser beam was directed at the sample from above, as shown in Figure 1. Two different lasers were used: one, a red diode laser at wavelength of $663 \mathrm{~nm}$ (custom built), and the other, a green Nd:YAG diode pumped solid state laser at $532 \mathrm{~nm}$ (Suwtech Laser, DPGL2200 Photop, Fuzhou, China). In accordance with the peak absorption spectrum of GNPs, the red laser was used for samples with gold nanorods and the green one for samples with gold nanospheres.

Temperature elevation over the sample was imaged using a radiometric thermal imaging camera (FLIR Systems Inc, Boston, MA, model A325). The camera has $320 \times 240$ pixels and a temperature sensitivity of $0.07^{\circ} \mathrm{C}$. The spatial resolution of the camera is $0.5 \mathrm{~mm}$. By adding an extra lens, it can achieve a spatial resolution of $0.1 \mathrm{~mm}$ at a working distance of $80 \mathrm{~mm}$. This kind of camera is sensitive to thermal radiation at a wavelength range of 8-14 $\mu \mathrm{m}$, and is completely blind to lasers and other light sources at the visible or near infrared spectral range. For each experiment, a few seconds of ambient temperature were recorded (at the center of the laser beam). Next, the samples were irradiated until reaching a saturation temperature. The irradiance was measured to be $10 \mathrm{~W} / \mathrm{cm}^{2}$ at the center of the beam.

\section{Results and discussion GNP synthesis and characterization}

Figure 2 shows the absorbance spectra (ultraviolet-visible spectrometer, Shimadzu, UV1650 PC, Tokyo, Japan) of the gold nanorods and gold nanospheres, and the wavelength of the lasers used (532 nm and $663 \mathrm{~nm}$ spectrophotometer, USB2000, Ocean Optics Inc, Dunedin FL). The absorption peaks of gold nanospheres and gold nanorods are around $515 \mathrm{~nm}$ and $690 \mathrm{~nm}$, respectively. Particle size, shape, and uniformity were measured using transmission electron microscopy, showing $30 \mathrm{~nm}$ gold nanospheres and $25 \mathrm{~nm} \times 65 \mathrm{~nm}$ gold nanorods, with a narrow size distribution ( $10 \%$, Figure 2 , right). In order to evaluate the potential of tumor margin delineation using targeted GNP with photothermal imaging techniques, phantoms containing different concentrations of gold nanospheres and gold nanorods, and cancer cells (A431) that were specifically targeted with gold nanorods, were irradiated, and their heating profiles were measured.

\section{Photothermal imaging of phantoms with GNPs}

Figure 3 shows the temperature difference profiles for irradiated gold nanorod solutions as a function of time for different concentrations of gold nanorods. As demonstrated, after less
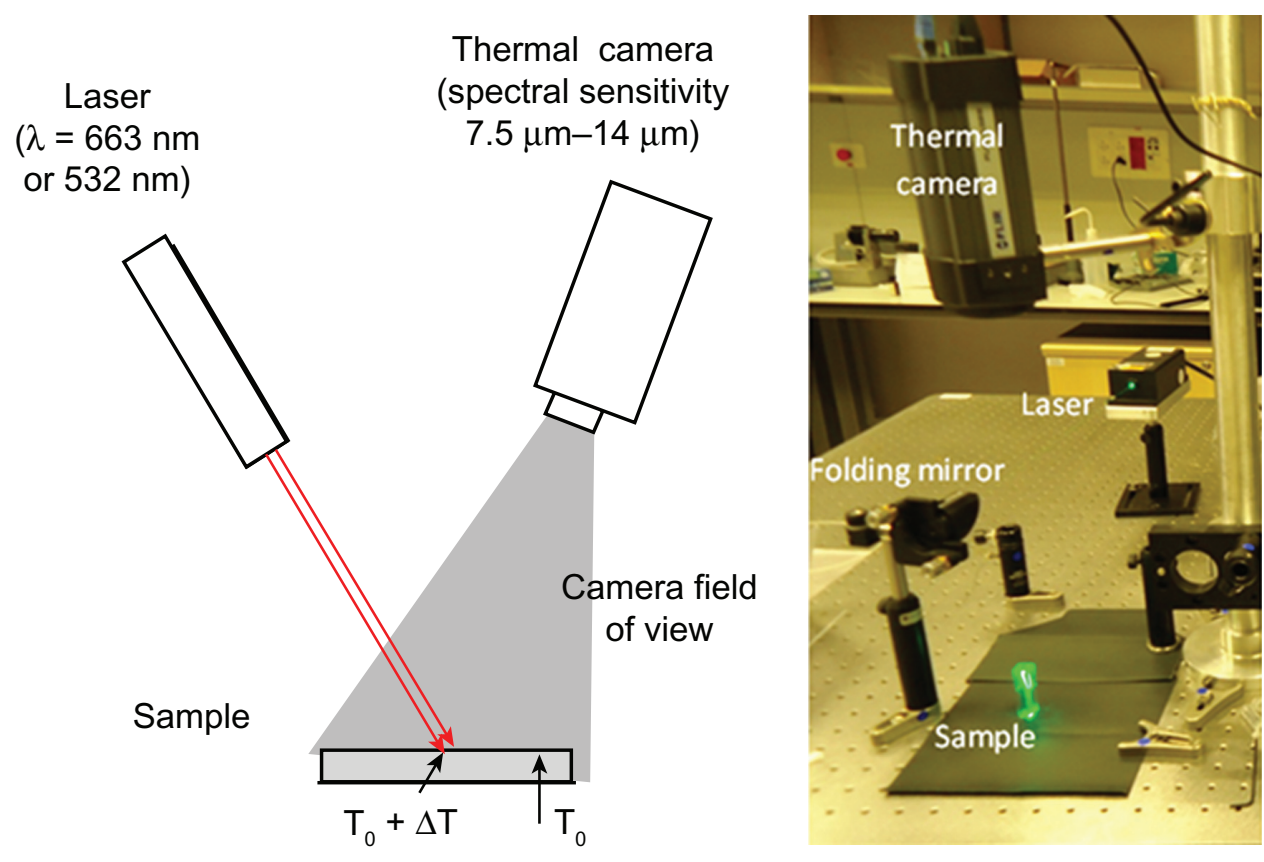

Figure I The optical setup. 

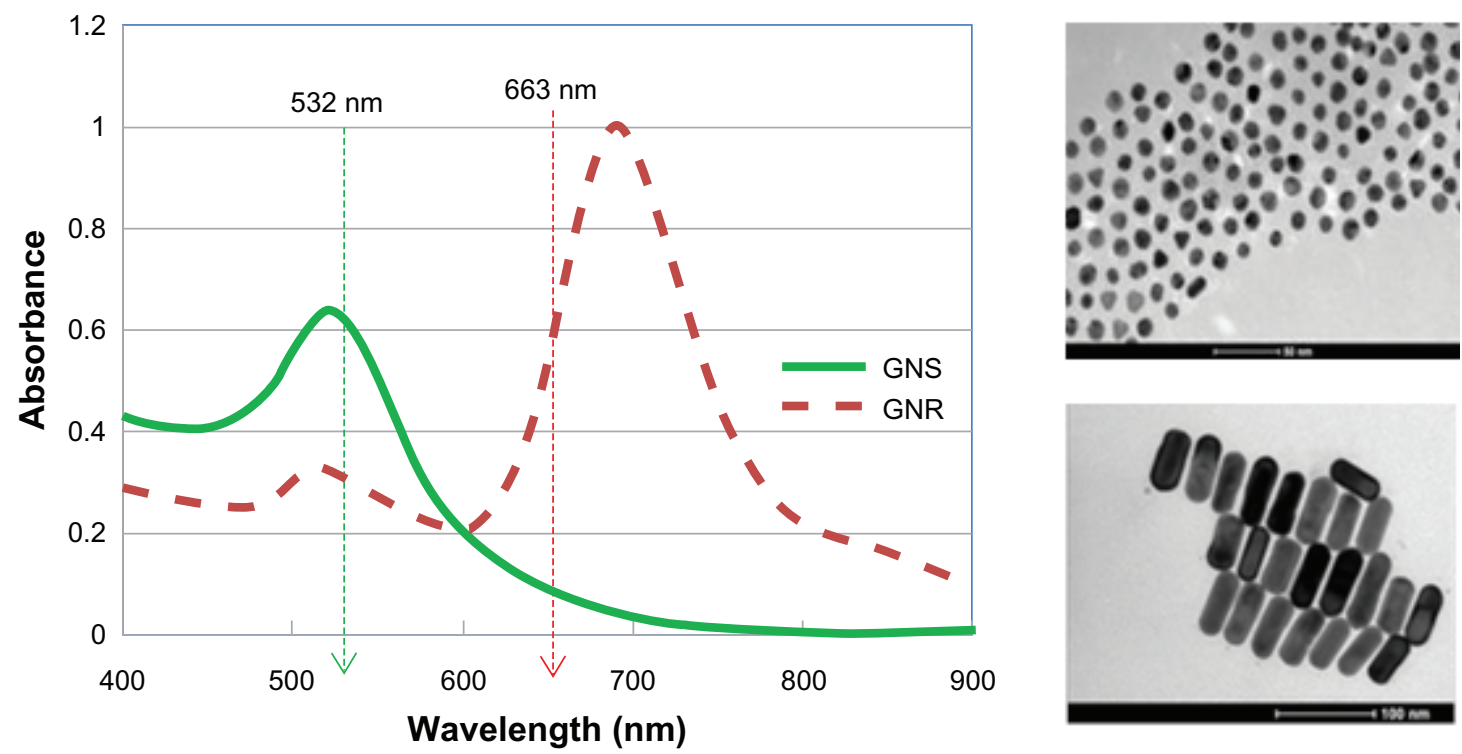

Figure 2 Left: Absorbance spectra of gold nanospheres (green) and gold nanorods (dashed red).

Notes: The wavelengths of the lasers are shown by the arrows. Right: transmission electron microscopy image of $30 \mathrm{~nm}$ gold nanospheres (upper figure, scale bar $100 \mathrm{~nm}$ ) and $25 \mathrm{~nm} \times 65 \mathrm{~nm}$ gold nanorods (lower figure, scale bar $100 \mathrm{~nm}$ ).

than 5 seconds of laser irradiation, the temperature profiles of the irradiated gold nanorod solutions were significantly different than those of the control solution without gold nanorods. The temperature of the control sample remained unchanged during the experiment, while the temperature of the gold nanorod samples was elevated. In addition, it can be seen that there was a positive correlation between the gold nanorod concentrations and temperature elevation. For the highest gold nanorod concentration $(0.1 \mathrm{mg} / \mathrm{mL})$, a temperature difference of about $14^{\circ} \mathrm{C}$ was observed after 10 seconds of irradiation, while for the lowest detectable concentration $(0.02 \mathrm{mg} / \mathrm{mL})$, a concentration that is clinically relevant, ${ }^{12,18,30}$ the temperature was elevated by about $1{ }^{\circ} \mathrm{C}$ after the same period of time.

The effect of laser wavelength on the heating properties of the gold nanospheres and gold nanorods was further investigated using green and red lasers. A red laser was used because the near infrared region of the spectrum provides maximal penetration of light due to relatively lower scattering and absorption from intrinsic tissue chromophores. In this region, the penetration depth of red light is up to $10 \mathrm{~cm}$, depending on the type of tissue. ${ }^{31} \mathrm{In}$ comparison, the tissue penetration depth of green light $(532 \mathrm{~nm})$ is very low (less than $500 \mu \mathrm{m}),{ }^{31}$ which could

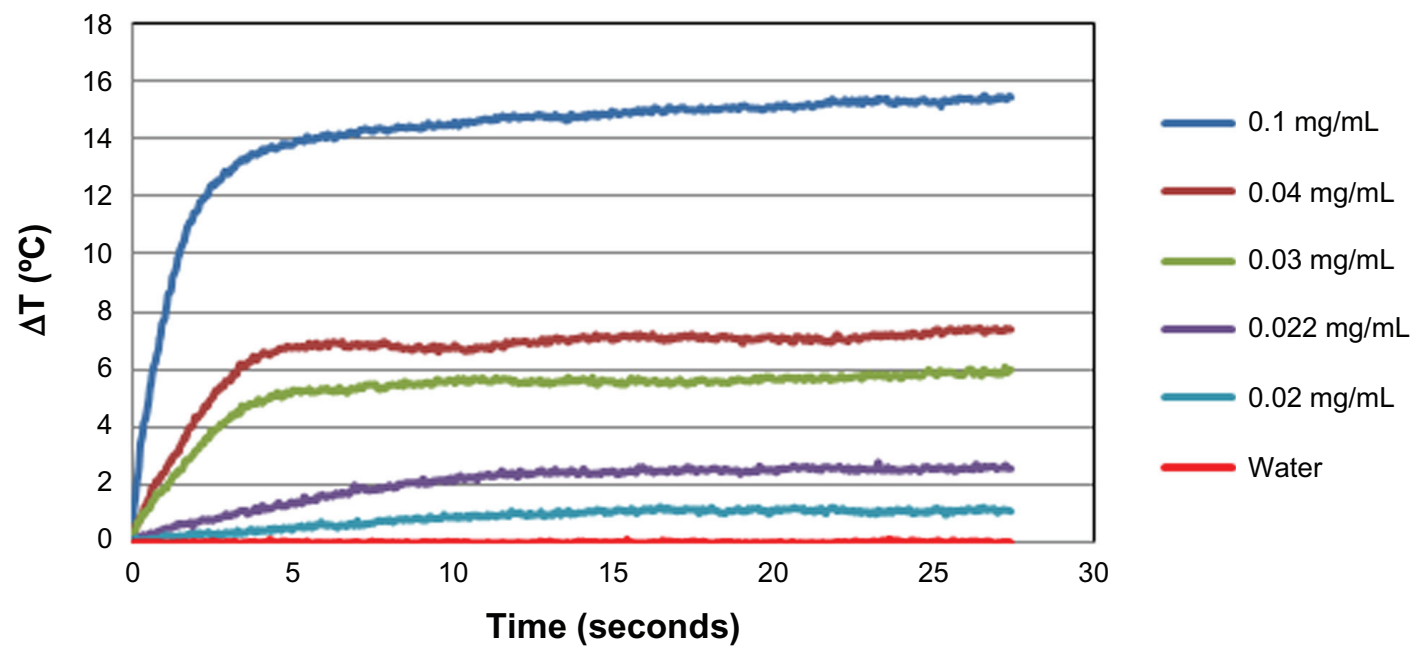

Figure 3 Temperature elevation as a function of irradiation time with the $663 \mathrm{~nm}$ laser for different concentrations of gold nanorods in aqueous solution. Note: The graph reaches a plateau after approximately 5 seconds. 
be useful for superficial lesions and margin detection during surgery.

Different concentrations of gold nanospheres (absorption peak at $515 \mathrm{~nm}$ ) and gold nanorods (absorption peak at $690 \mathrm{~nm}$ ) were irradiated with both $663 \mathrm{~nm}$ and $532 \mathrm{~nm}$ lasers for 30 seconds. As expected, the temperature profile was strongly affected by the optical properties of the nanoparticles. When gold nanospheres $(0.1 \mathrm{mg} / \mathrm{mL})$ were irradiated with $532 \mathrm{~nm}$, the temperature increased by $5.5^{\circ} \mathrm{C}$ after 5 seconds, while following irradiation with the $663 \mathrm{~nm}$ laser for the same period of time, a temperature elevation of only $2.5^{\circ} \mathrm{C}$ was observed (Figure 4A). Figure 4B depicts similar results for gold nanorods; when gold nanorods $(0.1 \mathrm{mg} / \mathrm{mL})$ were irradiated with $663 \mathrm{~nm}$, the temperature increased by $14^{\circ} \mathrm{C}$ after 5 seconds, while following irradiation with the $532 \mathrm{~nm}$ laser for the same period of time, a temperature elevation of only $4.5^{\circ} \mathrm{C}$ was observed. The temperature elevation of the samples when irradiated with lasers not at the GNP resonance peak can be explained by the tail of the resonance peak of the gold nanospheres at $690 \mathrm{~nm}$ and the "short axis" gold nanorod peak at $510 \mathrm{~nm}$. In addition, because of the larger cross-section of the gold nanorods compared with that of the gold nanospheres, ${ }^{15}$ the gold nanorods had a higher absorption efficiency, which was converted to thermal energy (Figure 4A and B).

This study further investigated the potential of this imaging modality to delineate tumor margins during surgery. Two half-cylindrical solid phantoms, one with gold nanorods
$(0.04 \mathrm{mg} / \mathrm{mL})$ and the other a phantom without gold nanorods, were bonded and irradiated with the $663 \mathrm{~nm}$ laser. As demonstrated in Figure 5, after 10 seconds of irradiation, the gold nanorod phantom region and the homogenous phantom are easily distinguishable. The temperature in the gold nanorod region was elevated by $3.5^{\circ} \mathrm{C}$ after 10 seconds of irradiation (Figure 5B), and by $9^{\circ} \mathrm{C}$ after 5 minutes of irradiation (Figure 5C). This concentration of gold nanorods was found to be clinically relevant in several in vivo studies ${ }^{32,33}$ and, therefore, demonstrates the ability to sensitively delineate tumor margins during surgery.

\section{Photothermal imaging of gold nanorod- targeted cancer cells}

In order to demonstrate the ability to perform photothermal imaging using targeted gold nanorods, the specificity of the interaction between the antibody-coated gold nanorods and the A431 SCC cancer cells (which highly express epithelial growth factor) was evaluated. Two types of gold nanorods were introduced to the cells; the first was specifically coated with anti-EGFR antibody, while the second, which was used as a negative control, was coated with a non-specific antibody (anti-rabbit IgG). Flame atomic absorption spectroscopy measurements (SpectrAA 140, Agilent Technologies, Santa Clara, CA) quantitatively demonstrated that active tumor targeting (anti-EGFRcoated gold nanorods) was significantly more specific than the control experiment (anti-rabbit IgG coated gold nanorods). The A431 cells took up $26.3 \pm 2.3 \mu \mathrm{g}$ of targeted

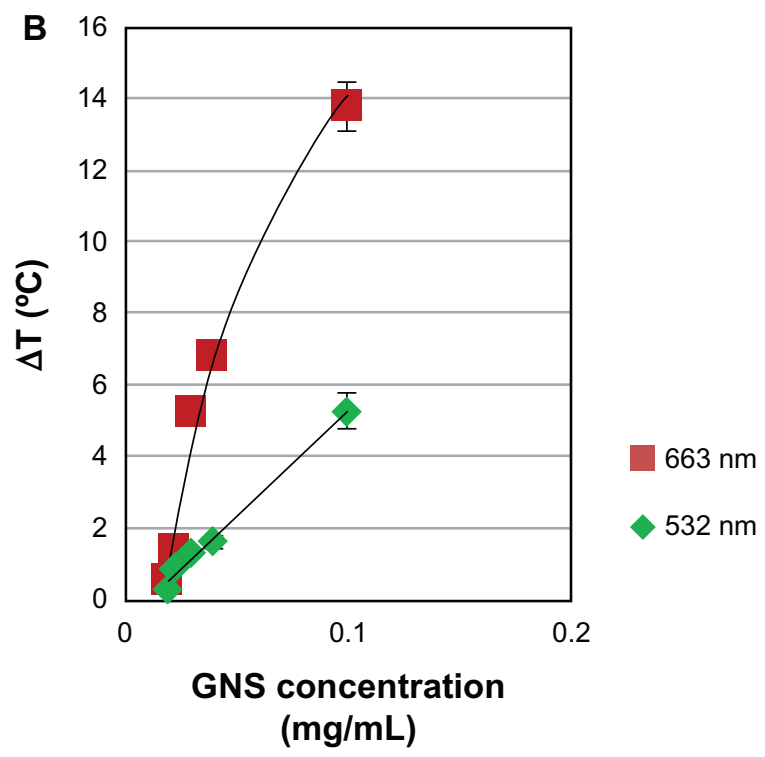

Figure 4 Temperature elevation as a function of concentrations of gold nanospheres $(\mathbf{A})$ and gold nanorods $(\mathbf{B})$ for the two lasers.

Notes: The time point for comparison was after 5 seconds of laser irradiation, when the temperature curves had reached a plateau. The laser optical intensity on the sample was $10 \mathrm{~W} / \mathrm{cm}^{2}$ for both lasers. 


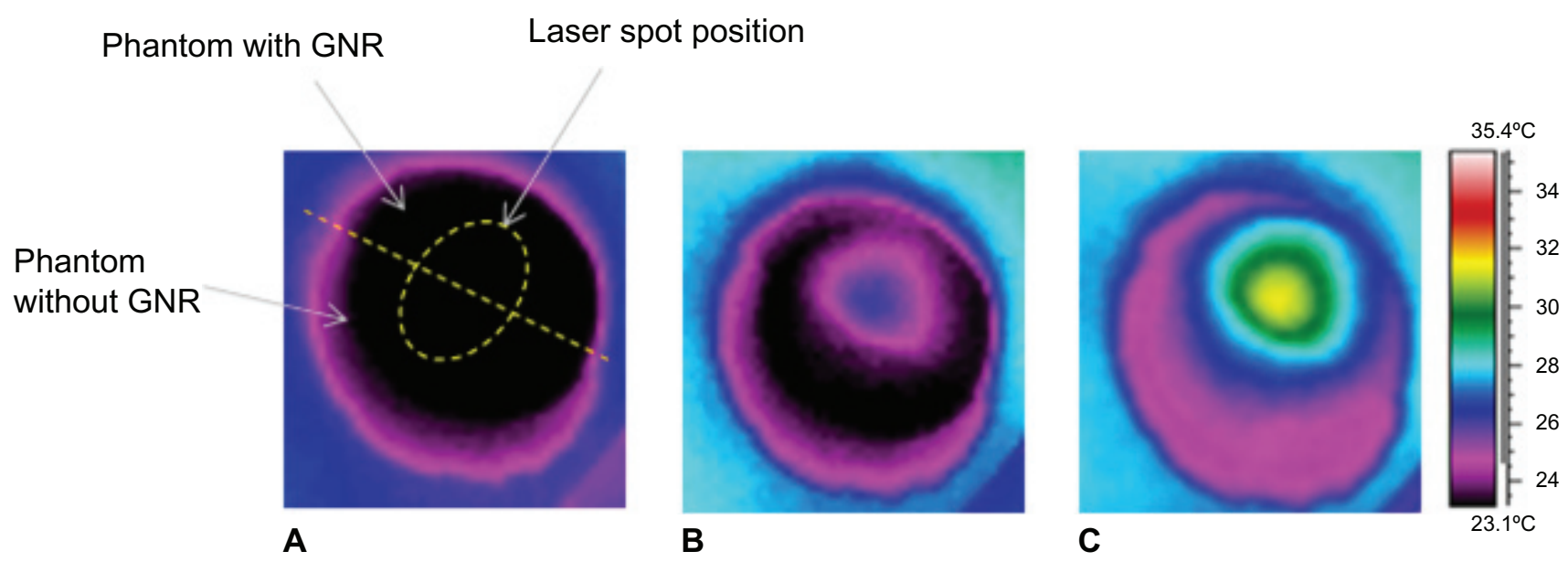

Figure $\mathbf{5}$ Thermal images of a sample made of two half-cylindrical solid phantoms joined together, one with gold nanorods and the other without. Image (A) was taken before laser irradiation. The border between the phantoms is shown by a dashed straight line. The elliptical contour shows the place where the laser beam hits the sample. Images (B) and (C) were taken after 10 seconds and 5 minutes of laser irradiation, respectively.

Note: It can be seen that the temperature in the part of the sample with the gold nanorods rises compared with that in the part without gold nanorods.

gold nanorods $\left(3.9 \times 10^{4}\right.$ gold nanorods per A431 cell), while parallel cells in the negative control experiment took up only $0.2 \pm 0.01 \mu \mathrm{g}$ of gold nanorods $\left(3.4 \times 10^{3}\right.$ gold nanorods per cell). Our results correlate well with those from previously published studies which report that head and neck squamous cell carcinoma expresses from $2 \times 10^{4}$ to $2 \times 10^{6}$ EGFR per cell. ${ }^{34,35}$

For photothermal imaging studies, gold nanorod-A431 bioconjugated cancerous cells $\left(2.5 \times 10^{6} / \mathrm{mL}\right)$ and control samples (A431 cells without gold nanorods) were irradiated for 6 minutes. As shown in Figure 6, in about 5 seconds, there is a distinct difference of $1{ }^{\circ} \mathrm{C}$ between the gold-targeted cells and the non-targeted cells. Following 30 seconds of laser irradiation, a temperature difference of $3^{\circ} \mathrm{C}$ has been observed, which is an appropriate temperature for imaging without affecting cell viability. ${ }^{36}$

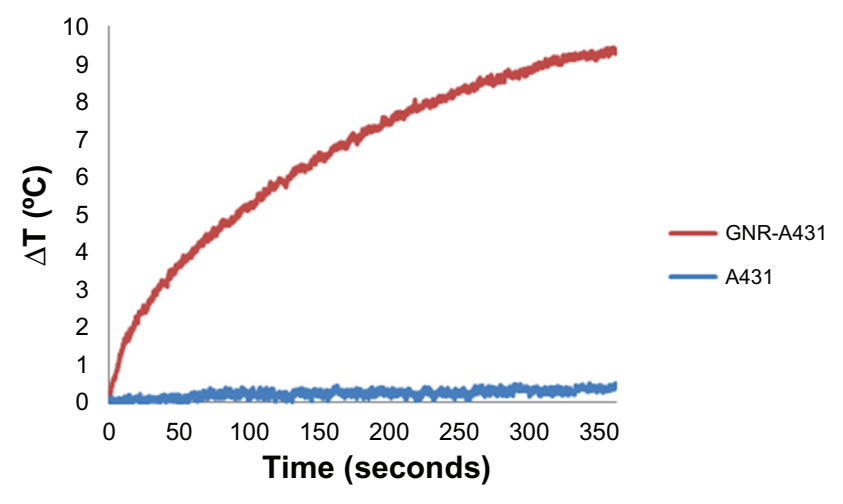

Figure 6 Temperature elevation of gold nanorods bioconjugated with an A43I cancer cell line compared with A43I cells without gold nanorods in solution.

Notes: It can be seen that the bioconjugated GNR-A43I has a distinctive heating profile compared with the $\mathrm{A} 43 \mathrm{I}$ cells.

\section{Conclusion}

In summary, this in vitro study demonstrates the feasibility of photothermal imaging of tumor margins when targeted with GNPs. By reducing the laser irradiation, GNP-targeted cancer cells can be detected without affecting cell viability. It has been shown that a low concentration of GNPs $(0.02 \mathrm{mg} / \mathrm{mL})$, lower than that found in several in vivo studies, ${ }^{18,32,33}$ can be easily detected. An important advantage of this imaging technique is the use of the absorption properties of GNPs rather than their scattering properties, leading to high contrast between targeted cancer cells and normal background tissue.

The possibility of combining photothermal imaging with photothermal therapy is an exciting approach toward theranostics. Additional laser irradiation following the detection of residual tumors adjacent to the primary tumor would lead to selective destruction of the cancer cells targeted with GNPs within the same clinical setting. We expect this in vitro proof of concept study will eventually lead to an intraoperative photothermal imaging technique which will assist surgeons in determining tumor margins accurately during surgery, leading to complete tumor resection and improved patient outcome.

\section{Acknowledgments}

This work was supported by the Elias, Genevieve, and Geogianna Atol Charitable Trust and the Katz Family Grant Incentive Program. The authors would like to thank Rinat Ankry and Vital Peretz for their help in the preparation of the GNPs and the phantoms.

\section{Disclosure}

The authors report no conflicts of interest in this work. 


\section{References}

1. World Health Organization. Cancer Fact Sheet 297, 2009. Available from: http://www.who.int/mediacentre/factsheets/fs297/en/index.html. Accessed July 23, 2012.

2. Smitt MC, Nowels K, Carlson RW, Jeffrey SS. Predictors of reexcision findings and recurrence after breast conservation. Int J Radiat Oncol Biol Phys. 2003;57(4):979-985.

3. Menes T, Tartter P, Bleiweiss I, Godbold J, Estabrook A, Smith S. The consequence of multiple re-excisions to obtain clear lumpectomy margins in breast cancer patients. Ann Surg Oncol. 2005;12(11):881-885.

4. Wilke LG, Brown JQ, Bydlon TM, et al. Rapid noninvasive optical imaging of tissue composition in breast tumor margins. Am J Surg. 2009;198(4):566-574.

5. Brown JQ, Bydlon TM, Richards LM, et al. Optical assesssment of tumor resection margins in the breast. IEEE J Sel Top Quantum Electron. 2010;16(3):530-544.

6. Allweis TM, Kaufman Z, Lelcuk S, et al. A prospective, randomized, controlled, multicenter study of a real-time, intraoperative probe for positive margin detection in breast-conserving surgery. Am J Surg. 2008;196(4):483-489.

7. van Dam GM, Themelis G, Crane LMA, et al. Intraoperative tumorspecific fluorescence imaging in ovarian cancer by folate receptor-[alpha] targeting: first in-human results. Nat Med. 2011;17(10):1315-1319.

8. von Maltzahn G, Centrone A, Park JH, et al. SERS-coded gold nanorods as a multifunctional platform for densely multiplexed near-infrared imaging and photothermal heating. Adv Mater. 2009;21(31):3175-3180.

9. Loo C, Lowery A, Halas N, West J, Drezek R. Immunotargeted nanoshells for integrated cancer imaging and therapy. Nano Lett. 2005;5(4): 709-711.

10. Huang X, Qian W, El-Sayed IH, El-Sayed MA. The potential use of the enhanced nonlinear properties of gold nanospheres in photothermal cancer therapy. Lasers Surg Med. 2007;39(9):747-753.

11. Terentyuk GS, Maslyakova GN, Suleymanova LV, et al. Laser-induced tissue hyperthermia mediated by gold nanoparticles: toward cancer phototherapy. J Biomed Opt. 2009;14(2):021016.

12. von Maltzahn G, Park JH, Agrawal A, et al. Computationally guided photothermal tumor therapy using long-circulating gold nanorod antennas. Cancer Res. 2009;69(9):3892-3900.

13. Tong L, Wei Q, Wei A, Cheng J-X. Gold nanorods as contrast agents for biological imaging: optical properties, surface conjugation and photothermal effects. Photochem Photobiol. 2009;85(1):21-32.

14. Gobin AM, Lee MH, Halas NJ, James WD, Drezek RA, West JL. Near-infrared resonant nanoshells for combined optical imaging and photothermal cancer therapy. Nano Lett. 2007;7(7):1929-1934.

15. Jain PK, Lee KS, El-Sayed IH, El-Sayed MA. Calculated absorption and scattering properties of gold nanoparticles of different size, shape, and composition: applications in biological imaging and biomedicine. J Phys Chem B. 2006;110(14):7238-7248.

16. Arai T, Hayashi T, Nakamura N, et al. Indocyanine green enhanced diode laser ablation for porcine gastric wall with ablation depth monitoring using scattering light. Paper presented at: Engineering in Medicine and Biology Society, 1998. Proceedings of the 20th Annual International Conference of the IEEE, October 29 to November 1, 1998.

17. Kim C, Cho EC, Chen J, et al. In vivo molecular photoacoustic tomography of melanomas targeted by bioconjugated gold nanocages. $A C S$ Nano. 2010;4(8):4559-4564.
18. Ankri R, Duadi H, Motiei M, Fixler D. In-vivo tumor detection using diffusion reflection measurements of targeted gold nanorods - a quantitative study. J Biophotonics. 2012;5(3):263-273.

19. Ankri R, Peretz V, Motiei M, Popovtzer R, Fixler D. A new method for cancer detection based on diffusion reflection measurements of targeted gold nanorods. Int J Nanomedicine. 2012;7:449-455.

20. Glazer ES, Curley SA. Radiofrequency field-induced thermal cytotoxicity in cancer cells treated with fluorescent nanoparticles. Cancer. 2010;116(13):3285-3293.

21. Biris AS, Boldor D, Palmer J, et al. Nanophotothermolysis of multiple scattered cancer cells with carbon nanotubes guided by time-resolved infrared thermal imaging. J Biomed Opt. 2009;14(2):021007.

22. Enüstün BV, Turkevich J. Coagulation of colloidal gold. J Am Chem Soc. $1963 ; 85(21): 3317-3328$.

23. Nikoobakht B, El-Sayed MA. Preparation and growth mechanism of gold nanorods (NRS) using seed-mediated growth method. Chem Mater. 2003;15:1957-1962.

24. Qian X, Peng X-H, Ansari DO, et al. In vivo tumor targeting and spectroscopic detection with surface-enhanced Raman nanoparticle tags. Nat Biotechnol. 2008;26(1):83-90.

25. Wang X, Qian X, Beitler JJ, et al. Detection of circulating tumor cells in human peripheral blood using surface-enhanced Raman scattering nanoparticles. Cancer Res. 2011;71(5):1526-1532.

26. Ai H, Fang M, Jones SA, Lvov YM. Electrostatic layer-by-layer nanoassembly on biological microtemplates: platelets. Biomacromolecules. 2002;3(3):560-564.

27. Dam JS, Pedersen CB, Dalgaard T, Fabricius PE, Aruna P, AnderssonEngels S. Fiber-optic probe for noninvasive real-time determination of tissue optical properties at multiple wavelengths. Appl Opt. 2001;40(7): 1155-1164.

28. Cubeddu R, Pifferi A, Taroni P, Torricelli A, Valentini G. A solid tissue phantom for photon migration studies. Phys Med Biol. 1997;42(10): 1971-1979.

29. Haigler H, Ash JF, Singer SJ, Cohen S. Visualization by fluorescence of binding and internalization of epidermal growth-factor in human carcinoma cells A-431. Proc Natl Acad Sci U S A. 1978;75(7): 3317-3321.

30. Li Z, Huang P, Zhang X, et al. RGD-conjugated dendrimer-modified gold nanorods for in vivo tumor targeting and photothermal therapy. Mol Pharm. 2009;7(1):94-104.

31. Weissleder R. A clearer vision for in vivo imaging. Nat Biotechnol. 2001;19(4):316-317.

32. Hainfeld JF, O'Connor MJ, Dilmanian FA, Slatkin DN, Adams DJ, Smilowitz HM. Micro-CT enables microlocalisation and quantification of Her2-targeted gold nanoparticles within tumour regions. Br J Radiol. 2011;84(1002):526-533.

33. Hainfeld JF, Slatkin DN, Focella TM, Smilowitz HM. Gold nanoparticles: a new x-ray contrast agent. Br J Radiol. 2006;79(939):248-253.

34. Todd R, Wong DTW. Epidermal growth factor receptor (EGFR) biology and human oral cancer. Histol Histopathol. 1999;14(2):491-500.

35. Stanton P, Richards S, Reeves J, et al. Epidermal growth-factor receptor expression by human squamous-cell carcinomas of the head and neck, cell-lines and xenografts. Br J Cancer. 1994;70(3):427-433.

36. Evdonin A, Kinev A, Tsupkina N, Guerriero V, Raynes DA, Medvedeva N. Extracellular HspBP1 and Hsp72 synergistically activate epidermal growth factor receptor. Biol Cell. 2009;101(6):351-360.

International Journal of Nanomedicine

\section{Publish your work in this journal}

The International Journal of Nanomedicine is an international, peerreviewed journal focusing on the application of nanotechnology in diagnostics, therapeutics, and drug delivery systems throughout the biomedical field. This journal is indexed on PubMed Central, MedLine, CAS, SciSearch $₫$, Current Contents ${ }^{\circledR} /$ Clinical Medicine,

\section{Dovepress}

Journal Citation Reports/Science Edition, EMBase, Scopus and the Elsevier Bibliographic databases. The manuscript management system is completely online and includes a very quick and fair peer-review system, which is all easy to use. Visit http://www.dovepress.com/ testimonials.php to read real quotes from published authors. 